\title{
A Role for Vascular Deficiency in Retinal Pathology in a Mouse Model of Ataxia-Telangiectasia
}

\author{
Dorit Raz-Prag, ${ }^{*}$ Ronit Galron, ${ }^{*}$ \\ Niva Segev-Amzaleg, ${ }^{*}$ Arieh S. Solomon, ${ }^{\dagger}$ \\ Yosef Shiloh, ${ }^{\ddagger}$ Ari Barzilai, ${ }^{*}$ and Dan Frenkel ${ }^{*}$ \\ From the Department of Neurobiology, George S. Wise Faculty of \\ Life Sciences, the Goldschlager Eye Institute, Sheba Medical \\ Center, ${ }^{\dagger}$ and the David and Inez Myers Laboratory for Cancer \\ Genetics, ${ }^{\ddagger}$ Department of Human Molecular Genetics and \\ Biochemistry, Sackler School of Medicine, Tel Aviv University, \\ Tel Aviv, Israel
}

Ataxia-telangiectasia is a multifaceted syndrome caused by null mutations in the $A T M$ gene, which encodes the protein kinase ATM, a key participant in the DNA damage response. Retinal neurons are highly susceptible to DNA damage because they are terminally differentiated and have the highest metabolic activity in the central nervous system. In this study, we characterized the retina in young and aged $\mathrm{Atm}$ deficient mice $\left(\mathrm{Atm}^{-/-}\right)$. At 2 months of age, angiography revealed faint retinal vasculature in $\mathrm{Atm}^{-/-}$animals relative to wild-type controls. This finding was accompanied by increased expression of vascular endothelial growth factor protein and mRNA. Fibrinogen, generally absent from wild-type retinal tissue, was evident in $\mathrm{Atm}^{-1-}$ retinas, whereas mRNA of the tight junction protein occludin was significantly decreased. Immunohistochemistry labeling for occludin in 6-month-old mice showed that this decrease persists in advanced stages of the disease. Concurrently, we noticed vascular leakage in $\mathrm{Atm}^{-/-}$retinas. Labeling for glial fibrillary acidic protein demonstrated morphological alterations in glial cells in $\mathrm{Atm}^{-/-}$retinas. Electroretinographic examination revealed amplitude aberrations in 2-month-old $\mathrm{Atm}^{-/-}$mice, which progressed to significant functional deficits in the older mice. These results suggest that impaired vascularization and astrocyte-endothelial cell interactions in the central nervous system play an important role in the etiology of ataxia-telangiectasia and that vascular abnormalities may underlie or aggravate neurodegeneration. (Am J Pathol 2011, 179:1533-1541; DOI: 10.1016/j.ajpath.2011.05.026)
Some brain disorders may have a vascular origin, ${ }^{1,2}$ and vascular diseases can be directly linked to neuronal and synaptic dysfunction through changes in the blood flow, increase in blood-brain barrier permeability, and in nutrient supply. ${ }^{3}$ A healthy brain relies on the proper function and communication of all cells comprising the neurovascular unit: neurons, astrocytes, brain endothelium, and vascular smooth muscle cells. ${ }^{4}$

Impaired genomic stability interferes with cellular homeostasis and poses a constant threat to cellular viability. ${ }^{5}$ The cell combats this threat by activating the DNA damage response (DDR), a complex signaling network that detects the DNA lesions, promotes their repair, and temporarily modulates cellular metabolism while the damage is being repaired. ${ }^{6}$ The DDR is vigorously activated by DNA double-strand breaks (DSBs), a particularly cytotoxic DNA lesion induced by ionizing radiation, radiomimetic chemicals, and oxygen radicals. ${ }^{7,8}$ The DNA damage response is a hierarchical process executed by sensor/mediator proteins that accumulate at DSB sites and by protein kinases that serve as transducers of the DNA damage alarm to numerous downstream effectors. ${ }^{6}$ The primary transducer of the cellular response to DSBs is the protein kinase ATM, which phosphorylates many key players in the various branches of the DDR. ${ }^{9}$

Ataxia-telangiectasia $(\mathrm{A}-\mathrm{T})$ is an autosomal recessive disorder caused by mutations in the ATM gene that encodes the ATM protein. ${ }^{10}$ A-T is characterized by progressive neurodegeneration affecting mainly the cerebellum, which develops into severe neuromotor dysfunction;

Supported by grants from the Human Frontier Science Program organization: CDA - 0019/2008-C; and Legacy Heritage Biomedical Science Partnership: 862/09. Work in the laboratory of A.B. was supported by research grants from the A-T Children's Project: 160240; the Israeli Ministry of Health: 3-00000-6068; Israel Science Foundation: 365/08; USIsrael Binational Science Foundation: 2005046; and the German-Israeli Foundation (GIF): 1-935-270.1/2006. Work in the laboratory of Y.S. was supported by the A-T Medical Research Foundation, the A-T Ease Foundation, and the Israel Cancer Research Fund. Y.S. is a Research Professor of the Israel Cancer Research Fund.

Accepted for publication May 9, 2011.

Address reprint requests to Dan Frenkel, Ph.D., Department of Neurobiology, George S. Wise Faculty of Life Sciences, Sherman Building, Room 424, Tel Aviv, Israel 69978. E-mail: dfrenkel@post.tau.ac.il. 
peripheral neuropathy; immunodeficiency that spans the B- and T-cell systems; thymic and gonadal atrophy; marked predisposition to lymphoreticular malignancies; and chromosomal fragility and acute sensitivity to ionizing radiation. Cultured ATM-deficient cells exhibit severe cellular sensitivity to DSB-inducing agents, with markedly defective DSB response.

DSBs are constantly induced in all body cells by metabolic byproducts such as oxygen radicals. Oxidative stress has been consistently associated with various neurodegenerative conditions. ${ }^{11-14}$ Indeed, there is substantial evidence for a role of oxidative damage in the progression of neurodegenerative disorders, including Parkinson's and Alzheimer's diseases. ${ }^{15}$ Similarly, elevated oxidative stress has been identified in several DNA repair deficiencies, including A-T. ${ }^{16-22}$ Notably, ATM has recently been shown to be activated by oxidative stress. ${ }^{23}$ Ocular tissues, especially the retina, are exposed to extremely high levels of reactive oxygen species. Nevertheless, retinal neurodegeneration has not been reported in A-T patients. The ocular manifestation of the disease reported to date is scleral telangiectasia ${ }^{24,25}$ and saccadic abnormalities. ${ }^{26}$ Moreover, no retinal pathology has been described to date in Atm-deficient mice despite their increased sensitivity to reactive oxygen species-inducing agents. ${ }^{27}$ We examined the link between retinal vascular pathology and function in young and aging Atm-deficient mice. We present evidence for vascular changes that accompany neuronal deficiencies in the retina.

\section{Materials and Methods}

\section{Animals}

$\mathrm{Atm}^{+/-}$mice ${ }^{28}$ were a generous gift from Dr. Anthony Wynshaw-Boris (University of California, San Diego, CA). Offspring of these mice were genotyped using PCRbased assays based on mouse-tail DNA prepared using the GenElute Mammalian Genomic DNA Miniprep kit (Sigma, St. Louis, MO). Two- and 6-month-old $\mathrm{Atm}^{-1-}$ mice were used for this study, and age-matched $\mathrm{Atm}^{+/+}$ littermates (WT) were used as controls. Mice were housed and maintained in the animal facility of Tel Aviv University, and all experiments complied with protocols approved by the university's animal care committee.

\section{Angiography}

Mice were anesthetized by an intraperitoneal injection of ketamine $(80 \mathrm{mg} / \mathrm{kg}$ ) and xylazine $(4 \mathrm{mg} / \mathrm{kg})$. An incision was made into the peritoneal cavity, and the diaphragm and pericardium were incised to visualize the heart. The mice were perfused slowly through the left ventricle with saline containing $25 \mathrm{mg}$ of high-molecular-mass $(2 \times$ $10^{6}$ ) fluorescein isothiocyanate-dextran (Sigma). Mice were sacrificed by $\mathrm{CO}_{2}$ inhalation; the eyes were enucleated and fixed in $4 \%$ paraformaldehyde for 1 hour. The retinas were gently separated from the eyecups and mounted on a microscope slide with mounting medium. Four incisions were made to flatten the retina, which was then covered with a coverslip. Imaging was performed on a fluorescence microscope.

\section{$R T-P C R$}

To determine mRNA levels, we isolated the eyecups and extracted the RNA using MasterPure RNA Purification kit (Epicentre Biotechnologies, Madison, WI). We determined the total RNA concentration with nanodrop analysis assay $(260 / 280 \mathrm{~nm})$ and further determined the purity of the extraction $(240 / 260 \mathrm{~nm}>1.95)$. The total RNA concentration was diluted with molecular water (DNase, RNase free; Sigma) to achieve approximately $500 \mathrm{ng} / \mathrm{mL}$. Samples containing equal amounts of total RNA ( 0.2 to 1 $\mu \mathrm{g}$ of RNA/sample) the type of were converted into CDNA using the Verso cDNA kit (AB1453/B). The template (diluted with the water) was incubated for 5 minutes at $70^{\circ} \mathrm{C}$ to remove secondary structure, and the corresponding cDNA was synthesized.

\section{Quantitative Real-Time PCR}

Samples were analyzed for quantification of mRNA expression via reverse transcription followed by quantitative real-time polymerase chain reaction using TaqMan (Absolute Blue QPCR ROX Mix, AB-4138; Abgene). RT-PCR assays were designed by Applied Biosystems (Foster City, CA) and compared with $\beta$-actin (ACTB) RNA levels. ${ }^{29}$ The comparative Ct method was used for quantification of transcripts according to the manufacturer's protocol. Measurement of $\Delta \mathrm{Ct}$ was performed in duplicate or triplicate. All reactions were performed with primer concentrations of $0.25 \mu \mathrm{mol} / \mathrm{L}$ in a total volume of $20 \mu \mathrm{L}$ of reaction.

\section{Western Blot Analysis}

Eyecups were washed with ice-cold PBS and homogenized in ice-cold homogenization buffer containing 1:50 phosphatase inhibitor cocktail (I and II; Sigma-Aldrich, St. Louis, MO) and 1:100 protease inhibitor cocktail. Protein concentration was determined using Bio-Rad Protein Assay (Hercules, CA). Western blot analysis was performed using $10 \%$ polyacrylamide gels. Each lane was loaded with an identical amount of protein extracts, which, following electrophoresis, were transferred into an immobilon polyvinylidene disulfide membrane (Millipore, Billerica, MA) for at least 12 hours at $200 \mathrm{~mA}$ or for 90 minutes at $280 \mathrm{~mA}$. Blots were stained with Ponceau to verify equal loading and transfer of proteins. Membranes were then probed with primary antibodies for vascular endothelial growth factor (VEGF) (1:1000; Abcam, Cambridge, UK) and fibrinogen (1:750; Dako, Glostrup, Denmark). Secondary antibody was goat anti-rabbit, IRDye infrared dye conjugated (Li-Cor antibody, 1:1000; Li-Cor Biosciences, Lincoln, NE) for 1 hour at room temperature. Blots were scanned using the Li-Cor imaging system, and band intensity was analyzed using Odyssey software (Odyssey Software, West Henrietta, NY). 


\section{Hemosiderin Labeling}

Flat-mount retinas from $\mathrm{Atm}^{-1-}$ and age-matched WT mice were stained for hemosiderin deposits with Prussian blue working solution (equal parts of freshly made $1 \%$ potassium ferrocyanide and $1 \%$ hydrochloric acid) for 60 minutes at room temperature, washed in deionized water, and counterstained with Nuclear Fast Red Blue-stained clusters of hemosiderin staining were qualitatively evaluated (presence/absence) from sections throughout the retina.

\section{Immunohistochemistry}

Anesthetized mice underwent intracardial perfusion with $200 \mathrm{~mL}$ of PBS to remove blood, and then with $25 \mathrm{~mL}$ of $4 \%$ paraformaldehyde. Eyes were enucleated and fixed in $4 \%$ paraformaldehyde for 1 hour at room temperature. The retinas were gently separated from the eyecups and submerged in $0.5 \%$ Triton overnight for permeabilization. The next day, the retinas were immersed in blocking medium (1\% bovine serum albumin, 10\% normal donkey serum, $0.25 \%$ Triton in PBS) for 2 hours, and then incubated with primary antibody in blocking medium for 1 hour at room temperature, followed by overnight at $4^{\circ} \mathrm{C}$. Retinas were then incubated with the secondary antibody for 2 hours at room temperature, and finally with Sytox blue (1:1000; Invitrogen, Carlsbad, CA) in a buffer containing Tris $10 \mathrm{mmol} / \mathrm{L}$, EDTA $1 \mathrm{mmol} / \mathrm{L}(\mathrm{pH}=7.5)$ for 20 minutes for nuclear staining. The stained retinas were placed in a drop of mounting medium on a microscope slide, incised for flattening, and covered with a coverslip. Primary antibodies used in this study included CD31 (rat anti-mouse, 1:100; BD Biosciences, Franklin Lakes, NJ), occludin (mouse anti-human, 1:100; Invitrogen), fibrinogen (rabbit anti-human, 1:250; Dako), and glial fibrillary acidic protein (GFAP) (rabbit anti-human, 1:500; Sigma). Secondary antibodies included AlexaFluor 488 and AlexaFluor 594 (1:250; Invitrogen). Imaging was performed on a Zeiss (Oberkochen, Germany) LSM-510 confocal microscope.

\section{Electroretinographic Analysis}

Animals were prepared under dim red light following overnight dark adaptation. Anesthesia was induced by intraperitoneal injection of ketamine $(80 \mathrm{mg} / \mathrm{kg})$ and $\mathrm{xy}$ lazine (4 mg/kg), and body temperature was maintained with a heating pad. Electroretinographic responses (ERGs) were recorded after fully dilating the pupils with topical corneal $0.5 \%$ tropicamide and $2.5 \%$ phenylephrine $\mathrm{HCl}$. A gold-wire loop electrode was placed on the cornea after topical $0.5 \%$ proparacaine $\mathrm{HCl}$ anesthesia. $\mathrm{A}$ gold-wire reference electrode was positioned to touch the sclera near the limbus of the eye, and a neutral electrode was placed on the tail. ERGs were recorded with the LKC system (LKC Technologies, Gaithersburg, MD) using ganzfeld stimulation. Dark-adapted responses were recorded across a 5 log unit range of stimulus intensity in 1 log unit steps up to maximum intensity of $1.4 \log \mathrm{cd} \bullet \mathrm{s} / \mathrm{m}^{2}$. Lightadapted responses were recorded against a constant
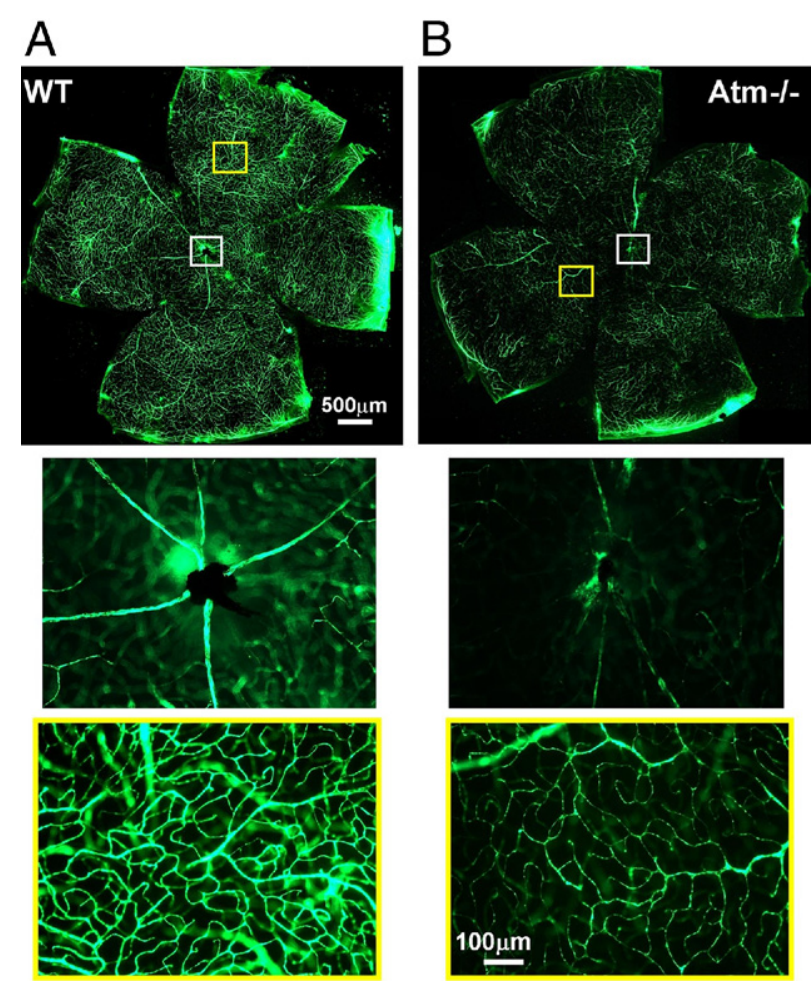

Figure 1. Attenuated blood vessels in retinas of $\mathrm{Atm}^{-1-}$ mice. Flat-mount retinas of 2-month-old WT $(\mathbf{A}, n=5)$ and $\mathrm{Atm}^{-/-}(\mathbf{B}, n=5)$ mice imaged with a fluorescent microscope following intracardial perfusion with dextranfluorescein. Insets show larger magnification of optic nerve region (white frame) and typical peripheral region (yellow frame).

white background light of $30 \mathrm{~cd} / \mathrm{m}^{2}$ that suppresses rod function. ERG responses were amplified and filtered (0.3 to $500 \mathrm{~Hz}$ ).

\section{Results}

\section{Increased Expression of VEGF in} Atm $^{-/-}$Retinas

A-T patients show impairment in scleral blood vessels. ${ }^{24,25,30}$ To assess similar pathological phenomena in the mouse model, we examined retinal vasculature in 2-month-old WT and $\mathrm{Atm}^{-1-}$ mice using fluorescent angiography. Blood vessels in the retinas of $\mathrm{Atm}^{-1-}$ mice were faintly illustrated in comparison to the WT retinas. Figure 1 shows that vessels in the $\mathrm{Atm}^{-1-}$ retinas appear constricted relative to WT and suggests that there might be changes in vessel density.

VEGF plays a major role in angiogenesis, and under pathological conditions, changes in VEGF levels can cause vascular dysfunction. ${ }^{31,32}$ Furthermore, it was suggested that VEGF may alter vascular permeability by regulating tight junctions. ${ }^{33}$ Therefore, we investigated whether the vascular differences we observed between retinas of $\mathrm{Atm}^{-1-}$ and $\mathrm{WT}$ mice may be related to changes in VEGF expression levels. Analysis of retinal mRNA levels revealed a significant increase of $40 \%$ in VEGF in the eyes of $\mathrm{Atm}^{-1-}$ mice relative to WT controls (Figure 2A). We further analyzed the VEGF levels using 

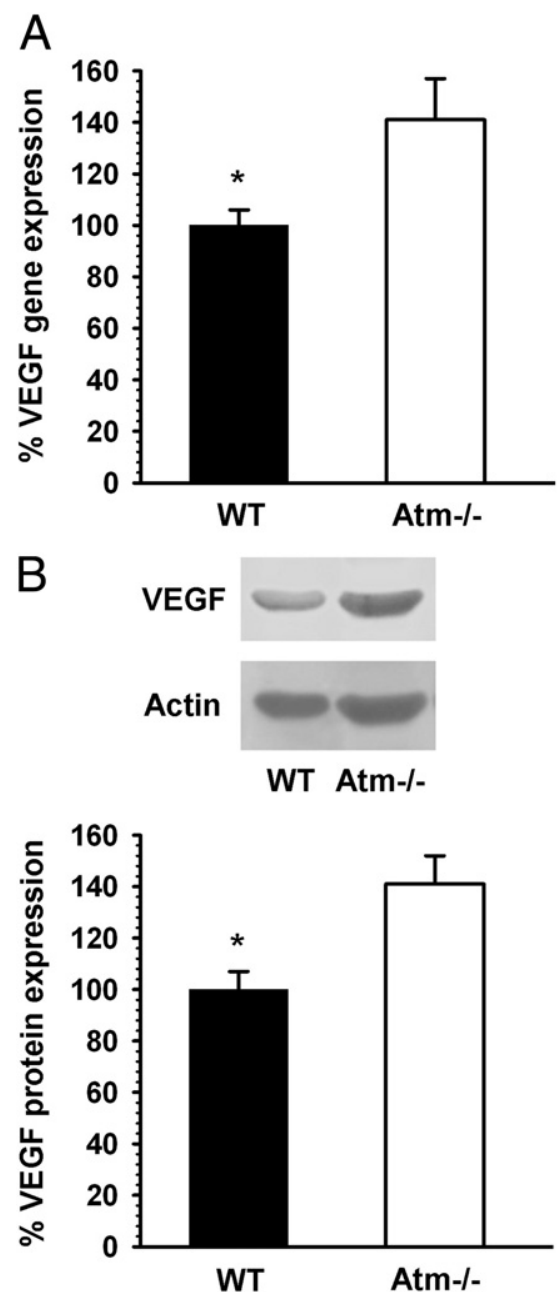

Figure 2. Increased VEGF levels in $\mathrm{Atm}^{-1-}$ mice. Real-time RT-PCR (A) and Western blot (B) analyses reveal significantly higher levels of VEGF in eyecups of $\mathrm{Atm}^{-1-}$ mice relative to VEGF levels in WT control mice. Statistical values were calculated by 2 -tailed Student's $t$-test. ${ }^{*} P<0.05$.

Western blot analysis and found that VEGF protein expression was significantly higher (35\% increase) in the retinal tissue of $\mathrm{Atm}^{-1-}$ mice than in WT retinas (Figure 2B). These results suggest that there is a linkage between VEGF expression and blood vessel pathology in $\mathrm{Atm}^{-1-}$ mice.

\section{Pathological Changes in Tight Junctions in Atm $^{-/-}$Mice}

Increased VEGF levels have been implicated as a detrimental factor causing neovascularization and vascular permeability in age-related macular degeneration. ${ }^{34}$ Increased vascular permeability is induced through a mechanism involving decreased expression of occludin in vascular endothelial cells ${ }^{35}$; therefore, we examined occludin expression in the ocular tissues. At 2 months of age, occludin mRNA was significantly decreased in $\mathrm{Atm}^{-1-}$ mice by an average of $60 \%$ compared to WT (Figure 3A). To test whether reduced occludin levels persist at older age, we examined occludin localization in the retinas of 6-month-old animals. Immunohistochemical analysis revealed distinct occludin labeling in blood vessels throughout the retina in WT mice, and only faint labeling in retinas of 6-month-old $\mathrm{Atm}^{-1-}$ mice (Figure $3 B$ ), suggesting that excessive expression of VEGF alters occludin expression resulting in blood vessel pathology.

\section{Microhemorrhage Incidents in Atm $^{-1-}$ Mice}

Fibrinogen is normally absent from healthy retinal tissue, but has been demonstrated in retinas treated with VEGF. ${ }^{36}$ It is a major player in pathologies involving damage to blood vessels. Using Western blot analysis, we found that protein levels of fibrinogen were significantly higher in retinas of 2-month-old $\mathrm{Atm}^{-1-}$ mice than in age-matched controls (Figure 4A). Immunohistochemical analyses of flat-mount retinas showed fibrinogen in association with retinal blood vessels in the $\mathrm{Atm}^{-1-}$ mice, whereas fibrinogen was only slightly evident in retinas of

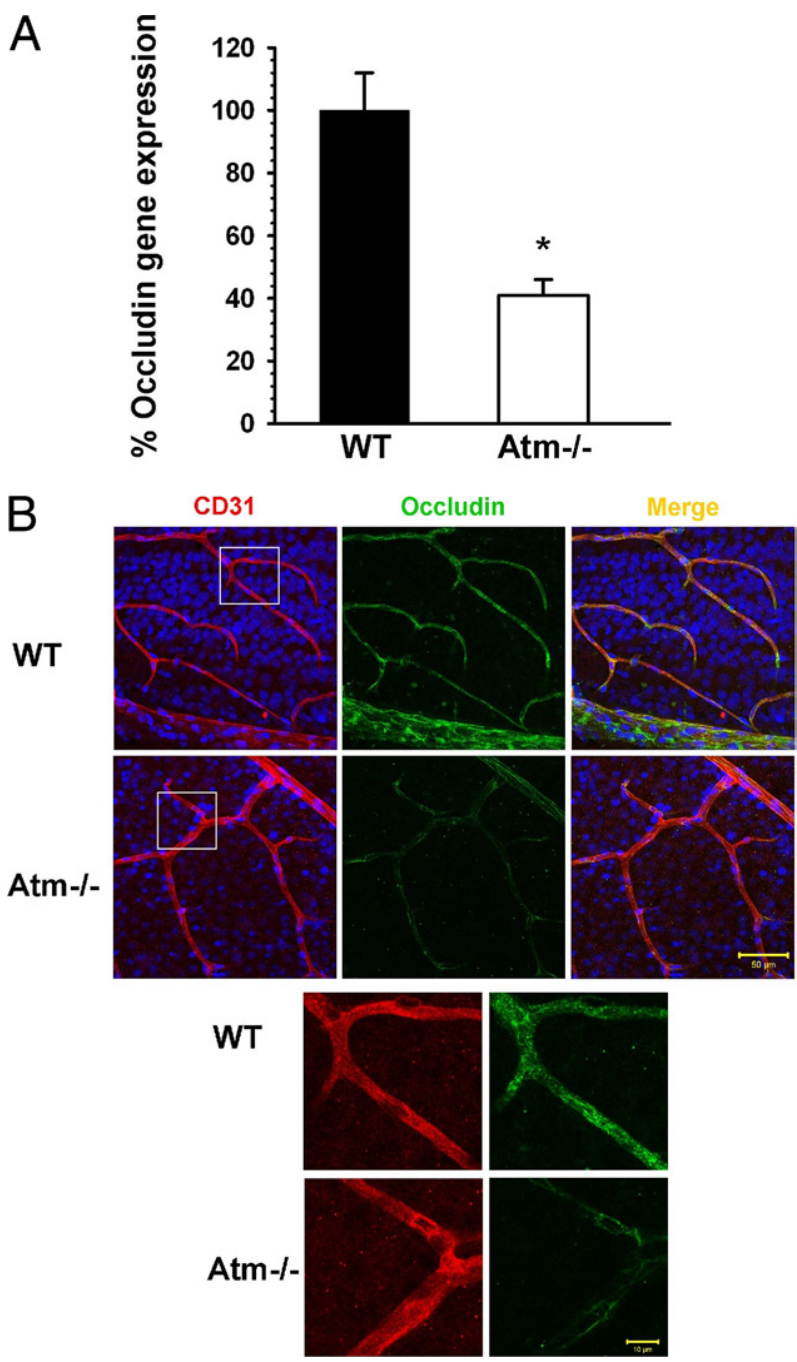

Figure 3. Reduced levels of occludin in $\mathrm{Atm}^{-/-}$mice. A: Real time RT-PCR analysis shows significantly lower levels of occludin in eyecups of $\mathrm{Atm}^{-/}$ mice relative to WT control mice at 2 months of age. Statistical values were calculated by 2 -tailed Student's $t$-test. ${ }^{*} P<0.0025$. B: Confocal images of flat-mount retinas of 6-month-old WT and $\mathrm{Atm}^{-1-}$ mice immunolabeled for CD31 (red) and occludin (green). Cell nuclei are labeled with Sytox Blue (blue). Upper scale bar: $50 \mu \mathrm{m}$, lower scale bar: $10 \mu \mathrm{m}$. 
A

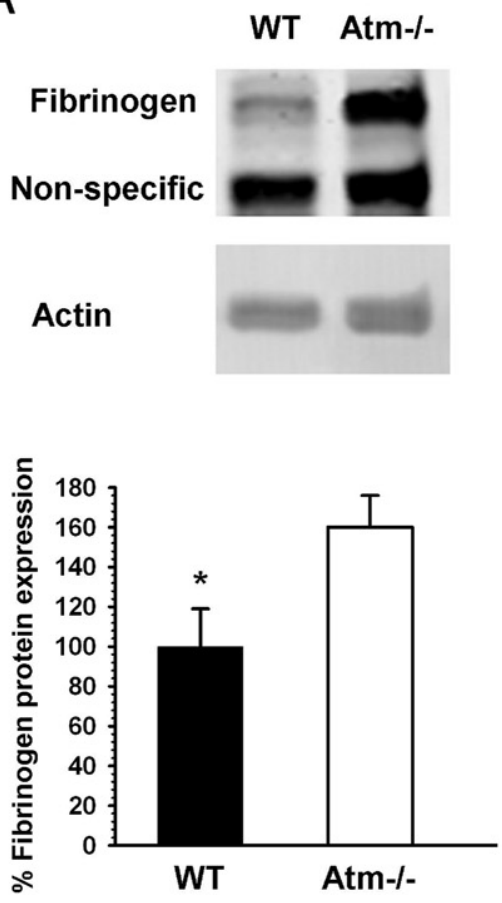

B
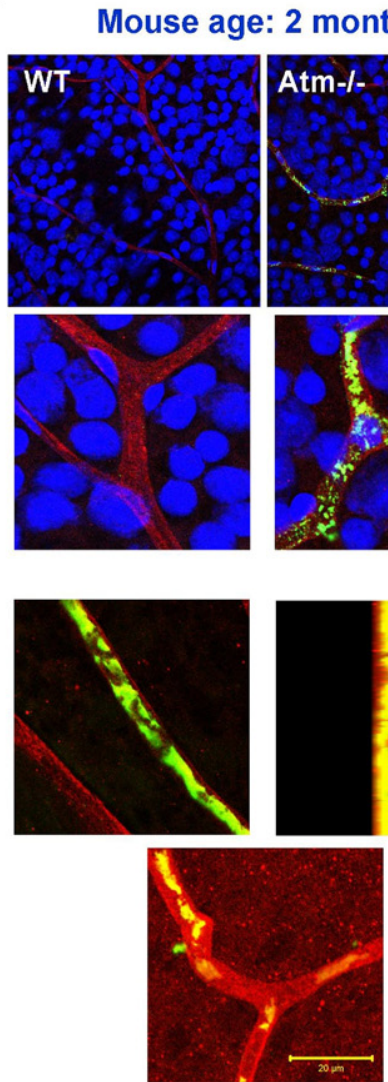

C Mouse age: 6 months
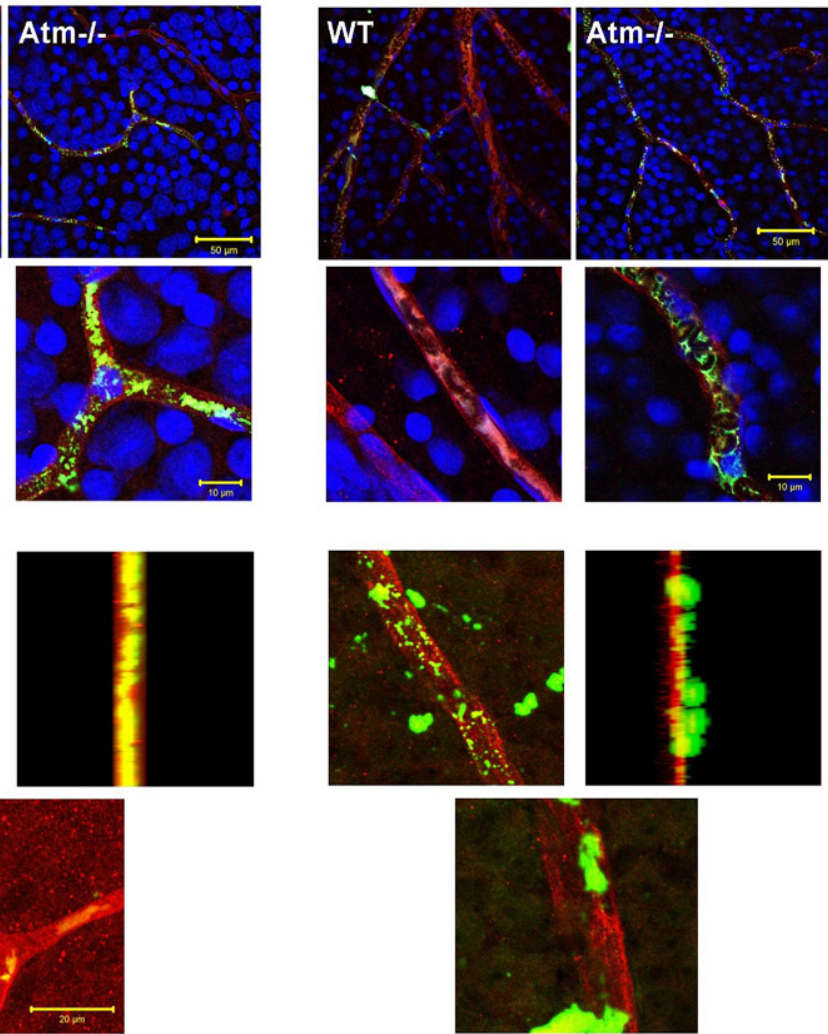

Figure 4. Increased fibrinogen expression in retinas of $\mathrm{Atm}^{-1-}$ mice. A: Western blot analysis depicts a statistically significant increase of $60 \%$ in fibrinogen level in the $\mathrm{Atm}^{-1-}$ retinas in comparison to age-matched controls. Statistical values were calculated by 2 -tailed Student's $t$-test. ${ }^{*} P<0.05$. B: Confocal images of flat-mount retinas of mice at 2 months of age show fibrinogen (green) in blood vessels (stained with the pan-endothelial marker CD31, red) of Atm $^{-1-}$ mice, but no labeling in WT controls. Cell nuclei are stained with Sytox Blue (blue). C: Similar imaging at 6 months of age reveals fibrinogen labeling external to blood vessels in a representative retina from an $\mathrm{Atm}^{-/-}$mouse. In the WT, fibrinogen labeling is absent or confined to the vessel. Upper scale bar: $50 \mu \mathrm{m}$, middle scale bar: $10 \mu \mathrm{m}$, lower scale bar: $20 \mu \mathrm{m}$.

control animals (Figure 4B). We further examined whether the pathological changes apparent at 2 months are progressive. We found a similar pattern in older mice (6 months of age). Furthermore, we found evidence of vascular leakage in these animals. Using confocal microscopy, we found that fibrinogen labeling was observed in clusters outside blood vessels in $\mathrm{Atm}^{-1-}$ retinas, whereas it colocalized with the endothelial cell marker in the retinas of WT mice (Figure 4C). Indeed, increases in fibrinogen levels, as well as reduced occludin content, have been previously associated with increased vascular permeability. ${ }^{35,37}$ To further examine vascular integrity by another parameter, we used the marker hemosiderin. Deposits of hemosiderin are breakdown products of hemoglobin and reflect microhemorrages that occurred previously. ${ }^{38}$ Immunohistological analysis revealed deposits of hemosiderin in $\mathrm{Atm}^{-1-}$ retinas as early as 2 months of age, whereas WT retinas lacked evidence of such deposits (Figure 5).

\section{Astrocyte-Vascular Pathology in $\mathrm{Atm}^{-1-}$ Mice}

Astrocyte-endothelial cell interaction plays a major role in the function of the vascular unit, and dysfunction in their interaction may lead to microhemorrhages. ${ }^{39}$ Furthermore, astrocytes are known to regulate the brain's endothelial barrier by releasing soluble factors such as VEGF. ${ }^{40}$ We investigated retinal astrocytes by examining the levels of GFAP in flat-mount retinas. Using confocal microscopy, we targeted the interaction of astrocytes (marked by GFAP) with endothelial cells (marked by CD31). As shown in Figure 6, in retinas of WT mice, the processes of the astrocytes appear to form an even network that encases the blood vessels, whereas in retinas of $\mathrm{Atm}^{-1-}$ mice, the astrocytic processes appear short and stubby, as found in cases of gliosis, and seem to be unable to form a continuous regular net alongside the blood vessels. These results suggest that Atm deficiency leads to pathological changes in astrocytes and impairs their ability to support the blood vessels.

\section{Vascular Pathology Results in Decreased Retinal Function in $\mathrm{Atm}^{-/-}$Mice}

We asked whether impairment in the astrocyte-endothelial cell interaction observed in $\mathrm{Atm}^{-1-}$ mice might lead to functional deficits. Retinal function was evaluated by ERG. Dark-adapted responses of 2-month-old mice 

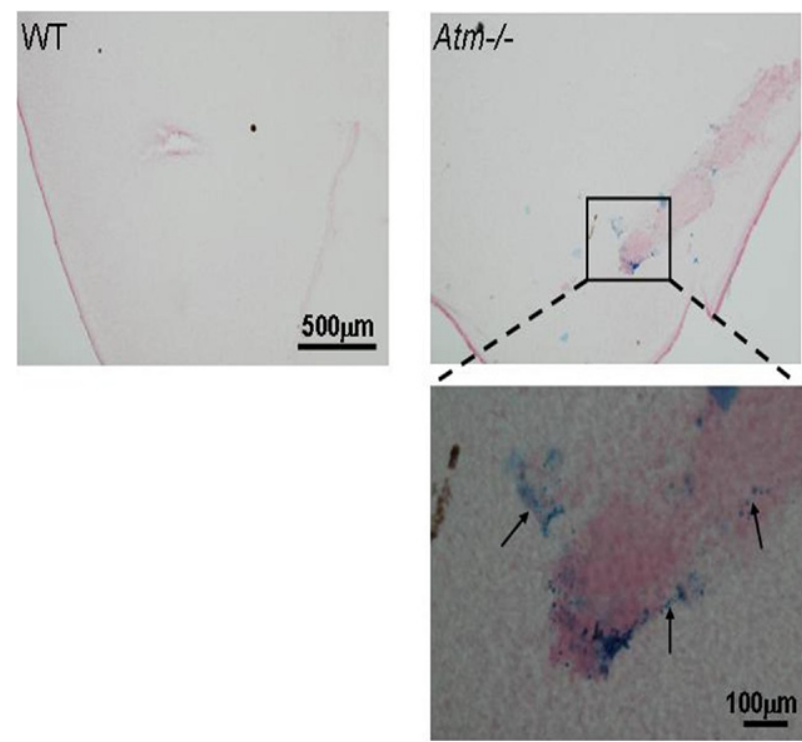

Figure 5. Vascular leakage in retinas of $\mathrm{Atm}^{-1-}$ mice. Whole-mount retinas of WT and $\mathrm{Atm}^{-/}$mice were stained for hemosiderin to indicate deposits resulting from microhemorrhages. The lower panel shows a larger magnification of the area marked with a rectangle in the image of $\mathrm{Atm}^{-/-}$retina Blue deposits of hemosiderin were evident in retinas of $\mathrm{Atm}^{-1-}$ mice (several indicated with arrows), but scarcely in retinas of WT mice.

showed no differences in a- and b-wave amplitudes between $\mathrm{Atm}^{-1-}$ and WT mice. In light-adapted responses, however, both a- and b-wave amplitudes of $\mathrm{Atm}^{-1-}$ mice were consistently lower than in WT across the range of stimulus intensities. b-Wave amplitude at maximal stimulus intensity was $378 \pm 30 \mu \mathrm{V}$ in the wild type, and $291 \pm$ $38 \mu \mathrm{V}$ in the $\mathrm{Atm}^{-1-}$ mice (Figure 7). To assess whether these early degenerative signs are progressive, we examined retinal function in 6-month-old mice. The a- and b-wave amplitudes of $\mathrm{Atm}^{-1-}$ retinal responses were consistently lower by $40 \%$ or more than the amplitudes in

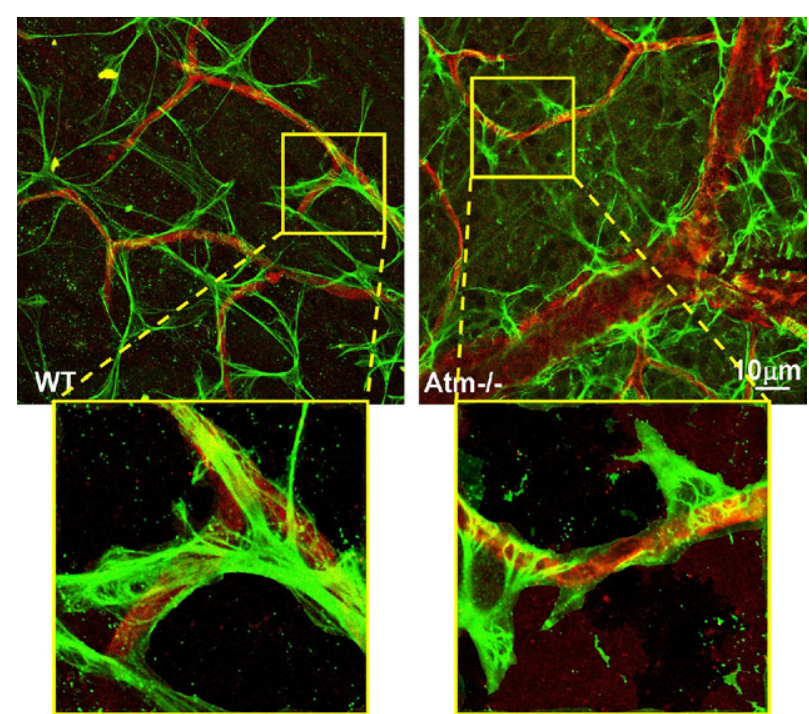

Figure 6. Glial cell alterations in retinas of $\mathrm{Atm}^{-1-}$ mice. Confocal images of flat-mount retinas from WT and $\mathrm{Atm}^{-/-}$mice, labeled for CD31 (red) and GFAP (green). Insets depict characteristic regions marked with a yellow frame at a larger magnification.

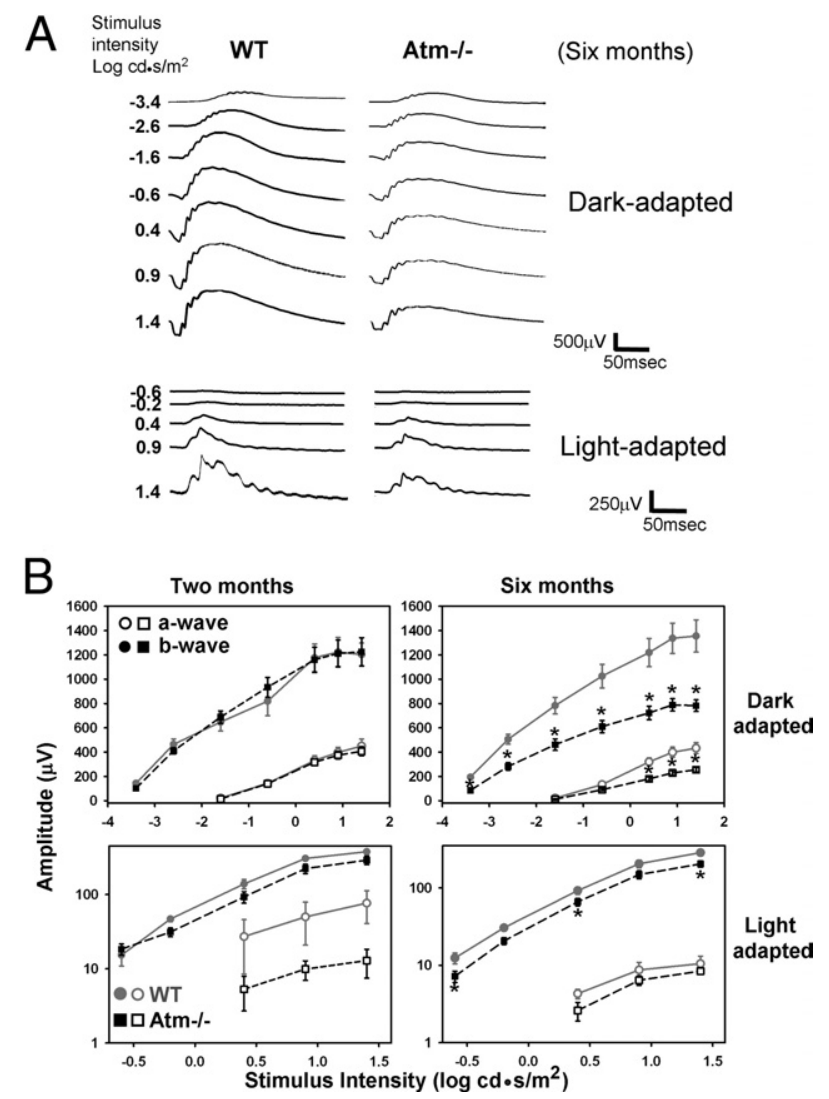

Figure 7. Retinal functional deficits in $\mathrm{Atm}^{-/-}$mice. A: Representative darkand light-adapted responses of 6-month-old WT and $\mathrm{Atm}^{-1-}$ mice. B: Average responses of WT (full gray line, circles, $n=5$ ) and $\mathrm{Atm}^{-1-}$ (broken black line, squares, $n=8$ ) mice at 2 months and 6 months (WT $n=5, \mathrm{Atm}^{-1}$ $n=5$ ) of age. Average and SE bars are shown for a-wave (open symbols) and b-wave (filled symbols). The a- and b-wave amplitudes were significantly higher in dark-adapted responses of WT mice compared to $\mathrm{Atm}^{-1-}$ mice at all stimulus intensities at 6 months. An asterisk denotes statistically significant amplitude difference at individual stimulus intensities in the graph of lightadapted responses. Statistical values were calculated by 2-tailed Student's t-test. ${ }^{*} P<0.05$

control age-matched mice in the dark-adapted ERG (Figure 7). These differences were statistically significant across the range of stimulus intensities. At maximal stimulus intensity, b-wave amplitude was $73 \%$ higher in WT $(1355 \pm 133 \mu \mathrm{V})$ than in Atm $^{-1-}$ mice $(783 \pm 48 \mu \mathrm{V}, P<$ 0.01). Similarly, b-wave amplitudes of the light-adapted responses were lower in $\mathrm{Atm}^{-1-}$ mice than in the responses of the control mice. At maximal intensity, b-wave amplitude in WT mice was $40 \%$ higher than in $\mathrm{Atm}^{-1-}$ mice.

\section{Discussion}

Here, we show that Atm deficiency in mice leads to impaired retinal vasculature. Furthermore, we found significant elevation in astrocyte-secreted VEGF, which might play a role in vascular pathology. Collectively, our data suggest an important role for astrocyte-vascular interaction in Atm-deficient mice and probably A-T patients.

There is growing attention to the role of glial cells in neuropathologies. ${ }^{41}$ Transgenic and knockout mouse models for certain astrocyte-specific proteins demon- 
strated neuropathologies. ${ }^{42,43}$ Astrocyte abnormalities and their influence on Purkinje cells have also been reported in $\mathrm{Atm}^{-1-}$ cells. ${ }^{41,44,45}$ Electron microscopy observations have detected structural activation of glial cells in Atm knockout mice. ${ }^{46}$ Ultrastructural alterations in astrocytes have been demonstrated alongside neuronal degenerative processes in $\mathrm{Atm}^{-1-}$ mice in cerebellar tissue. ${ }^{46}$ Furthermore, astrocytes from $\mathrm{Atm}^{-/-}$mice exhibited growth arrest and growth defects, which may be due to oxidative stress. ${ }^{41,47}$ Retinal neurons are terminally differentiated and are therefore, like other neurons in the brain, irreplaceable. The ongoing visual processes require large amounts of energy, which cause the retina to have the highest oxygen consumption in the mammalian brain. ${ }^{27,48,49}$ This creates a stressful environment, with the metabolic byproducts that are formed, primarily reactive oxygen species, constantly attacking neuroretinal DNA. ${ }^{27,50,51}$ Like the rest of the central nervous system, the retina depends on glia, mostly Muller cells and astrocytes, for proper function. We have discovered that the pathological appearance of astrocytes along the retinal blood vessel may result in microhemorrhage incidents.

ATM controls DDR, which is, in turn, critically important for normal retinal development and maintenance. Retinal and choroidal vascular abnormalities were associated with Atm missense variants. ${ }^{52,53}$ Our findings support this and show vascular abnormalities in the mouse model of Atm. These blood vessel abnormalities are likely to result in impaired oxygen diffusion to the retina. The resulting hypoxia can strongly up-regulate VEGF. ${ }^{31,32,54}$ VEGF is a major factor in different types of angiogenic disorders including those associated with cancer, ischemia, and inflammation. ${ }^{55}$ It is a member of a group of growth factors and hormones that alter vascular permeability by regulating tight junctions. ${ }^{33}$

In the eye, excessive VEGF has been implicated as a detrimental factor causing neovascularization and vascular leakage in age-related macular degeneration ${ }^{34}$ and in proliferative retinopathies. ${ }^{56}$ VEGF is not only up-regulated in response to hypoxia and nonperfusion, but may also be an underlying cause of them. ${ }^{57}$ In addition, VEGF can induce hypertrophy of endothelial cells of retinal capillaries, at the expense of lumen diameter. ${ }^{57,58}$ We provide evidence for an increase in VEGF in the retinas of $\mathrm{Atm}^{-\prime-}$ mice. This can account for the vasoconstriction and vascular leakage that we found in the retinas of $\mathrm{Atm}^{-1-}$ mice.

Fibrinogen, a factor that is intertwined with VEGF, may also have multiple effects on the retinal abnormalities in the $\mathrm{Atm}^{-/-}$mice that we report here. We report a significant increase in fibrinogen levels, as early as 2 months of age and ongoing to advanced stages of the disease. Increased fibrinogen content leads to its binding to endothelial receptors, intercellular adhesion molecule-1 $\left(\right.$ ICAM- ${ }^{59,60}$ ) and $\alpha 5 \beta 1$ integrin. ${ }^{60,61}$ This induces increased formation of F-actin, leading to stiffening of cells and actin filament retraction. ${ }^{37,62-66}$ Furthermore, increased levels of fibrinogen have been shown to downregulate endothelial tight junction proteins. ${ }^{67}$ Both of these processes lead to widening of interendothelial junctions and increased vascular leakage in the paracellular route, as demonstrated by fibrinogen and hemosiderin labeling in this study. Fibrinogen can also induce vasoconstriction through the production of endothelin$1 .^{63}$ This, too, could be manifested in the vessel narrowing evident in the angiography imaging.

One of the tight junction proteins that is affected by fibrinogen as well as by VEGF and that contributes to vascular permeability is occludin. ${ }^{67}$ We demonstrated here that occludin is significantly reduced in the retinas of $\mathrm{Atm}^{-/-}$mice at 2 months of age. In parallel, we found indications for interstitial accumulation of blood by hemosiderin staining. However, the angiographic and fibrinogen evaluation at 2 months did not reveal clear evidence of vascular leakage as one might expect. A study on occludin-null mice showed that occludin is not required for maintaining functional tight junctions, and that cells of these mice form structurally intact tight junctions despite the absence of occludin. ${ }^{68,69}$ It is possible that in our case, too, the reduction in occludin is compensated for by the presence of other tight junction proteins at this relatively early stage of the disease. The symptomatic picture is aggravated with time, as shown by fibrinogen labeling at 6 months, perhaps as other components of the tight junction are also impaired.

High levels of the activated phosphorylated form of ATM were detected in the cytoplasm of mouse photoreceptors. ${ }^{27}$ Cerebellar cells of $\mathrm{Atm}^{-1-}$ mice spontaneously develop elevated levels of oxidative DNA damage, ${ }^{15,70,71}$ and it is reasonable that photoreceptor cells will suffer similar damage and show reduced performance. The functional changes that we report here demonstrate progressive conspicuous neuroretinal deficiencies. We found that ERG at 2 months points to early signs of degeneration. In a progressive stage of the disease, at 6 months of age, significant functional defects are evident that involve both rod and cone systems. Amplitude reductions in the b-wave suggest that the damage may be more extensive and include the inner layers of the retina beyond the photoreceptors as well. These findings concur with subtle neurological abnormalities reported previously, including electrophysiological deficiencies. ${ }^{15,22,46,72-77}$

The symptomatic picture presented in A-T patients is complex and multifaceted, partly progressive, and occasionally fixed over a limited period of time. The diversity of systems affected by the disease and their interconnections makes it difficult to determine which of the disease manifestations is primary and which reflects added systemic complications. The diagnosis of A-T based on its clinical manifestations is challenging. ${ }^{78}$ Ocular symptoms of telangiectasia and saccadic abnormalities in A-T patients generally appear 4 to 5 years after first signs of ataxia. ${ }^{26}$

The abnormalities that we present here encompass neuronal, glial, and vascular changes. We suggest that the changes in the retinal glio-neurovascular unit are underlying factors that aggravate the functional deficits that we report in advanced stages of the disease. We suggest that the retina could serve as a useful window to central nervous system pathology in A-T models in future 
studies, as signs are apparent at the young age of 2 months. The additional ocular alterations described here, if replicated in human patients, could assist in earlier diagnosis of the disease.

\section{References}

1. Forstl $\mathrm{H}$, Howard R: Recent studies on dementia senilis and brain disorders caused by atheromatous vascular disease: by A. Alzheimer, 1898. Alzheimer Dis Assoc Disord 1991, 5:257-264

2. Baldwin RC, O'Brien J: Vascular basis of late-onset depressive disorder. Br J Psychiatry 2002, 180:157-160

3. Zlokovic BV: The blood-brain barrier in health and chronic neurodegenerative disorders. Neuron 2008, 57:178-201

4. Bell RD, Zlokovic BV: Neurovascular mechanisms and blood-brain barrier disorder in Alzheimer's disease, Acta Neuropath 2009, 118: 103-113.

5. Jackson SP, Bartek J: The DNA-damage response in human biology and disease. Nature 2009, 461:1071-1078

6. Ciccia A, Elledge SJ: The DNA damage response: making it safe to play with knives. Mol Cell 2010, 40:179-204

7. Bassing $\mathrm{CH}$, Alt FW: The cellular response to general and programmed DNA double strand breaks. DNA Repair (Amst) 2004, 3:781-796

8. Hartlerode AJ, Scully R: Mechanisms of double-strand break repair in somatic mammalian cells. Biochem J 2009, 423:157-168

9. Lavin MF, Kozlov S: ATM activation and DNA damage response. Cell Cycle 2007, 6:931-942

10. Lavin MF: Ataxia-telangiectasia: from a rare disorder to a paradigm for cell signalling and cancer. Nat Rev Mol Cell Biol 2008, 9:759-769

11. Halliwell B: Oxidative stress and neurodegeneration: where are we now? J Neurochem 2006, 97:1634-1658

12. Perry JJ, Fan L, Tainer JA: Developing master keys to brain pathology, cancer and aging from the structural biology of proteins controlling reactive oxygen species and DNA repair. Neuroscience 2007, 145:1280-1299

13. Ryter SW, Kim HP, Hoetzel A, Park JW, Nakahira K, Wang X, Choi AM: Mechanisms of cell death in oxidative stress. Antioxid Redox Signal 2007, 9:49-89

14. Trushina E, McMurray CT: Oxidative stress and mitochondrial dysfunction in neurodegenerative diseases. Neuroscience 2007, 145: 1233-1248

15. Barlow C, Dennery PA, Shigenaga MK, Smith MA, Morrow JD, Roberts LJ 2nd, Wynshaw-Boris A, Levine RL: Loss of the ataxia-telangiectasia gene product causes oxidative damage in target organs. Proc Natl Acad Sci U S A 1999, 96:9915-9919

16. Barzilai A, Biton S, Shiloh Y: The role of the DNA damage response in neuronal development, organization and maintenance. DNA Repair (Amst) 2008, 7:1010-1027

17. Barzilai A, Rotman G, Shiloh Y: ATM deficiency and oxidative stress: a new dimension of defective response to DNA damage. DNA Repair (Amst) 2002, 1:3-25

18. Chen P, Peng C, Luff J, Spring K, Watters D, Bottle S, Furuya S, Lavin MF: Oxidative stress is responsible for deficient survival and dendritogenesis in purkinje neurons from ataxia-telangiectasia mutated mutant mice. J Neurosci 2003, 23:11453-11460

19. Ito K, Hirao A, Arai F, Matsuoka S, Takubo K, Hamaguchi I, Nomiyama K, Hosokawa K, Sakurada K, Nakagata N, Ikeda Y, Mak TW, Suda T: Regulation of oxidative stress by ATM is required for self-renewal of haematopoietic stem cells. Nature 2004, 431:997-1002

20. Karanjawala ZE, Murphy N, Hinton DR, Hsieh CL, Lieber MR: Oxygen metabolism causes chromosome breaks and is associated with the neuronal apoptosis observed in DNA double-strand break repair mutants. Curr Biol 2002, 12:397-402

21. Suraweera A, Becherel OJ, Chen P, Rundle N, Woods R, Nakamura J, Gatei M, Criscuolo C, Filla A, Chessa L, Fusser M, Epe B, Gueven N, Lavin MF: Senataxin, defective in ataxia oculomotor apraxia type 2 , is involved in the defense against oxidative DNA damage. J Cell Biol 2007, 177:969-979

22. Watters DJ: Oxidative stress in ataxia telangiectasia. Redox Rep 2003, 8:23-29
23. Guo Z, Kozlov S, Lavin MF, Person MD, Paull TT: ATM activation by oxidative stress. Science 2010, 330:517-521

24. Crawford TO, Mandir AS, Lefton-Greif MA, Goodman SN, Goodman BK, Sengul H, Lederman HM: Quantitative neurologic assessment of ataxia-telangiectasia. Neurology 2000, 54:1505-1509

25. Lavin MF, Gueven N, Bottle S, Gatti RA: Current and potential therapeutic strategies for the treatment of ataxia-telangiectasia. Br Med Bull 2007, -82:129-14781

26. Crawford TO: Ataxia telangiectasia. Semin Pediatr Neurol 1998 5:287-294

27. Leemput J, Masson C, Bigot K, Errachid A, Dansault A, Provost A, Gadin S, Aoufouchi S, Menasche M, Abitbol M: ATM localization and gene expression in the adult mouse eye. Mol Vis 2009, 15:393-416

28. Barlow C, Hirotsune S, Paylor R, Liyanage M, Eckhaus M, Collins F, Shiloh Y, Crawley JN, Ried T, Tagle D, Wynshaw-Boris A: Atmdeficient mice: a paradigm of ataxia telangiectasia. Cell 1996, 86: $159-171$

29. Frenkel D, Puckett L, Petrovic S, Xia W, Chen G, Vega J, DembinskyVaknin A, Shen J, Plante M, Burt DS, Weiner HL: A nasal proteosome adjuvant activates microglia and prevents amyloid deposition. Ann Neurol 2008, 63:591-601

30. Biton S, Barzilai A, Shiloh Y: The neurological phenotype of ataxiatelangiectasia: solving a persistent puzzle. DNA Repair (Amst) 2008, 7:1028-1038

31. Detmar M, Brown LF, Berse B, Jackman RW, Elicker BM, Dvorak HF, Claffey KP: Hypoxia regulates the expression of vascular permeability factor/vascular endothelial growth factor (VPF/VEGF) and its receptors in human skin. J Invest Dermatol 1997, 108:263-268

32. Shweiki D, Itin A, Soffer D, Keshet E: Vascular endothelial growth factor induced by hypoxia may mediate hypoxia-initiated angiogenesis. Nature 1992, 359:843-845

33. Harhaj NS, Antonetti DA: Regulation of tight junctions and loss of barrier function in pathophysiology. Int J Biochem Cell Biol 2004, 36:1206-1237

34. Blaauwgeers HG, Holtkamp GM, Rutten $H$, Witmer AN, Koolwijk $P$, Partanen TA, Alitalo K, Kroon ME, Kijlstra A, van Hinsbergh VW, Schlingemann RO: Polarized vascular endothelial growth factor secretion by human retinal pigment epithelium and localization of vascular endothelial growth factor receptors on the inner choriocapillaris. Evidence for a trophic paracrine relation, Am J Pathol 1999, 155:421-428

35. Antonetti DA, Barber AJ, Khin S, Lieth E, Tarbell JM, Gardner TW: Vascular permeability in experimental diabetes is associated with reduced endothelial occludin content: vascular endothelial growth factor decreases occludin in retinal endothelial cells. Penn State Retina Research Group. Diabetes 1998, 47:1953-1959

36. Hofman P, Blaauwgeers HG, Vrensen GF, Schlingemann RO: Role of VEGF-A in endothelial phenotypic shift in human diabetic retinopathy and VEGF-A-induced retinopathy in monkeys. Ophthalmic Res 2001, 33:156-162

37. Tyagi N, Roberts AM, Dean WL, Tyagi SC, Lominadze D: Fibrinogen induces endothelial cell permeability. Mol Cell Biochem 2008, 307: 13-22

38. Viswanathan A, Chabriat H: Cerebral microhemorrhage. Stroke 2006, 37:550-555

39. Lifshitz V, Frenkel D: Animal models for cerebrovascular impairment and its relevance in vascular dementia. Cognitive Impairment: Causes, Diagnosis and Treatments. Edited by Landow. ML New York, Nova Biomedical Books, 2009, pp 1-20.

40. Fruttiger M: Development of the retinal vasculature. Angiogenesis $2007,10: 77-88$

41. Kim J, Wong PK: Oxidative stress is linked to ERK1/2-p16 signalingmediated growth defect in ATM-deficient astrocytes. J Biol Chem 2009, 284:14396-14404

42. Otani N, Nawashiro H, Fukui S, Ooigawa H, Ohsumi A, Toyooka T, Shima K, Gomi H, Brenner M: Enhanced hippocampal neurodegeneration after traumatic or kainate excitotoxicity in GFAP-null mice. J Clin Neurosci 2006, 13:934-938

43. Pardo AC, Wong V, Benson LM, Dykes M, Tanaka K, Rothstein JD, Maragakis NJ: Loss of the astrocyte glutamate transporter GLT1 modifies disease in SOD1(G93A) mice. Exp Neurol 2006, 201 : 120-130 
44. Liu N, Stoica G, Yan M, Scofield VL, Qiang W, Lynn WS, Wong PK: ATM deficiency induces oxidative stress and endoplasmic reticulum stress in astrocytes. Lab Invest 2005, 85:1471-1480

45. Wang XF, Cynader MS: Astrocytes provide cysteine to neurons by releasing glutathione. J Neurochem 2000, 74:1434-1442

46. Kuljis RO, Xu Y, Aguila MC, Baltimore D: Degeneration of neurons, synapses, and neuropil and glial activation in a murine Atm knockout model of ataxia-telangiectasia. Proc Natl Acad Sci U S A 1997, 94:12688-12693

47. Gosink EC, Chong MJ, McKinnon PJ: Ataxia telangiectasia mutated deficiency affects astrocyte growth but not radiosensitivity. Cancer Res 1999, 59:5294-5298

48. Yu DY, Cringle SJ: Oxygen distribution and consumption within the retina in vascularised and avascular retinas and in animal models of retinal disease. Prog Retin Eye Res 2001, 20:175-208

49. Yu DY, Cringle SJ: Retinal degeneration and local oxygen metabolism. Exp Eye Res 2005, 80:745-751

50. Reme CE, Braschler UF, Roberts J, Dillon J: Light damage in the rat retina: effect of a radioprotective agent (WR-77913) on acute rod outer segment disk disruptions. Photochem Photobiol 1991, 54: $137-142$

51. Specht S, Leffak M, Darrow RM, Organisciak DT: Damage to rat retinal DNA induced in vivo by visible light. Photochem Photobiol 1999, 69:91-98

52. Barbazetto IA, Room M, Yannuzzi NA, Barile GR, Merriam JE, Bardal AM, Freund KB, Yannuzzi LA, Allikmets R: ATM gene variants in patients with idiopathic perifoveal telangiectasia. Invest Ophthalmo Vis Sci 2008, 49:3806-3811

53. Mauget-Faysse M, Vuillaume M, Quaranta M, Moullan N, Angele S, Friesen MD, Hall J: Idiopathic and radiation-induced ocular telangiectasia: the involvement of the ATM gene. Invest Ophthalmo Vis Sci 2003, 44:3257-3262

54. Kerbel RS: Tumor angiogenesis. N Engl J Med 2008, 358:2039-2049

55. Carmeliet P: Angiogenesis in health and disease. Nat Med 2003 , 9:653-660

56. Aiello LP, Avery RL, Arrigg PG, Keyt BA, Jampel HD, Shah ST, Pasquale LR, Thieme H, Iwamoto MA, Park JE, et al.: Vascular endothelial growth factor in ocular fluid of patients with diabetic retinopathy and other retinal disorders. N Engl J Med 1994, 331:1480-1487

57. Tolentino MJ, Miller JW, Gragoudas ES, Jakobiec FA, Flynn E, Chatzistefanou K, Ferrara N, Adamis AP: Intravitreous injections of vascular endothelial growth factor produce retinal ischemia and microangiopathy in an adult primate. Ophthalmology 1996, 103:1820-1828

58. Hofman P, van Blijswijk BC, Gaillard PJ, Vrensen GF, Schlingemann $\mathrm{RO}$ : Endothelial cell hypertrophy induced by vascular endothelia growth factor in the retina: new insights into the pathogenesis of capillary nonperfusion. Arch Ophthalmol 2001, 119:861-866

59. D'Souza SE, Byers-Ward VJ, Gardiner EE, Wang H, Sung SS: Identification of an active sequence within the first immunoglobulin domain of intercellular cell adhesion molecule-1 (ICAM-1) that interacts with fibrinogen. J Biol Chem 1996, 271:24270-24277

60. Plow EF, Haas TA, Zhang L, Loftus J, Smith JW: Ligand binding to integrins. J Biol Chem 2000, 275:21785-21788

61. Luscinskas FW, Lawler J: Integrins as dynamic regulators of vascular function. FASEB J 1994, 8:929-938
62. Ehringer WD, Yamany S, Steier K, Farag A, Roisen FJ, Dozier A, Miller FN: Quantitative image analysis of F-actin in endothelial cells. Microcirculation 1999, 6:291-303

63. Lominadze D, Saari JT, Percival SS, Schuschke DA: Proinflammatory effects of copper deficiency on neutrophils and lung endothelial cells. Immunol Cell Biol 2004, 82:231-238

64. Mehta D, Malik AB: Signaling mechanisms regulating endothelial permeability. Physiol Rev 2006, 86:279-367

65. Qiao RL, Yan W, Lum H, Malik AB: Arg-Gly-Asp peptide increases endothelial hydraulic conductivity: comparison with thrombin response. Am J Physiol 1995, 269:C110-117

66. Trepat X, Grabulosa M, Buscemi L, Rico F, Farre R, Navajas D: Thrombin and histamine induce stiffening of alveolar epithelial cells. J Appl Physiol 2005, 98:1567-1574

67. Patibandla PK, Tyagi N, Dean WL, Tyagi SC, Roberts AM, Lominadze D: Fibrinogen induces alterations of endothelial cell tight junction proteins. J Cell Physiol 2009, 221:195-203

68. Saitou M, Fujimoto K, Doi Y, Itoh M, Fujimoto T, Furuse M, Takano H, Noda T, Tsukita S: Occludin-deficient embryonic stem cells can differentiate into polarized epithelial cells bearing tight junctions. J Cell Biol 1998, 141:397-408

69. Saitou M, Furuse M, Sasaki H, Schulzke JD, Fromm M, Takano H, Noda T, Tsukita S: Complex phenotype of mice lacking occludin, a component of tight junction strands. Mol Biol Cell 2000, 11:41314142

70. Abraham RT: Cell cycle checkpoint signaling through the ATM and ATR kinases. Genes Dev 2001, 15:2177-2196

71. Reliene R, Fischer E, Schiestl RH: Effect of N-acetyl cysteine on oxidative DNA damage and the frequency of DNA deletions in atmdeficient mice. Cancer Res 2004, 64:5148-5153

72. Allen DM, van Praag H, Ray J, Weaver Z, Winrow CJ, Carter TA, Braquet R, Harrington E, Ried T, Brown KD, Gage FH, Barlow C: Ataxia telangiectasia mutated is essential during adult neurogenesis. Genes Dev 2001, 15:554-566

73. Borghesani PR, Alt FW, Bottaro A, Davidson L, Aksoy S, Rathbun GA, Roberts TM, Swat W, Segal RA, Gu Y: Abnormal development of Purkinje cells and lymphocytes in Atm mutant mice, Proc Natl Acad Sci U S A 2000, 97:3336-3341

74. Chiesa N, Barlow C, Wynshaw-Boris A, Strata P, Tempia F: Atmdeficient mice Purkinje cells show age-dependent defects in calcium spike bursts and calcium currents. Neuroscience 2000, 96:575-583

75. Eilam R, Peter Y, Elson A, Rotman G, Shiloh Y, Groner Y, Segal M: Selective loss of dopaminergic nigro-striatal neurons in brains of Atm-deficient mice. Proc Natl Acad Sci U S A 1998, 95:12653-12656

76. Eilam R, Peter $Y$, Groner $Y$, Segal M: Late degeneration of nigrostriatal neurons in ATM-/- mice. Neuroscience 2003, 121:83-98

77. Mount HT, Martel JC, Fluit P, Wu Y, Gallo-Hendrikx E, Cosi C, Marien MR: Progressive sensorimotor impairment is not associated with reduced dopamine and high energy phosphate donors in a model of ataxia-telangiectasia. J Neurochem 2004, 88:1449-1454

78. Cabana MD, Crawford TO, Winkelstein JA, Christensen JR, Lederman HM: Consequences of the delayed diagnosis of ataxia-telangiectasia. Pediatrics 1998, 102:98-100 